\title{
From an integrated optimal design to a systemic optimization of a stand alone passive wind turbine system with storage
}

\author{
M. Belouda, J. Belhadj \\ University of Tunis, DGE-ESSTT \\ University of Tunis El Manar, ENIT, L.S.E.B.P. 37, 1002 \\ Tunis, Tunisie
}

\author{
A. Jaafar, B. Sareni, X. Roboam \\ University of Toulouse, LAPLACE UMR CNRS-INP- \\ UPS, ENSEEIHT 2, Rue Charles Camichel 31071 \\ Toulouse, France
}

\begin{abstract}
In this paper, the authors report the development of a Systemic Optimization Process (SOP) devoted to a passive wind turbine system with electrochemical storage bank. Aim of the SOP is to find the optimal combination and sizing among sets of system components, that meets the desired system requirements; with the lowest system owning cost. The passive wind system associated to the storage bank interacts with wind and load cycles (deterministic data). Sets of passive wind turbines are obtained through an Integrated Optimal Design (IOD) process. The system cost model is inspired from constructor data for the wind turbines and related to the battery cycles for the storage bank. An optimization problem is developed and performed using an exhaustive research. The optimization results are finally exposed and discussed.
\end{abstract}

Keywords-passive wind turbine, systemic optimization, integrated Optimal Design, battery cycles, owning cost $t$

\section{INTRODUCTION}

Providing consumers in remote areas with reliable and cheap electricity becomes a priority in several developed and undeveloped countries such the case of isolated cities in Tunisia. Wind energy systems with storage are among the most competitive alternatives for electrifying remote consumers and they are widely used in both autonomous or grid connected applications. However, the drawbacks of such sources are that their owning cost still very expensive and that the wind system alone is unable to protect the battery against deep discharges (requirement of an additional dynamic source of energy or an optimal wind system design to extend the battery bank life $[1,2]$. Recently, several researches based on global optimization techniques are focused on the design of the optimal system configurations which meet the load demand for a given weather data [3-5]. This paper suggests a systemic methodology for designing the optimal combination and sizing of passive wind turbine associated to an electrochemical storage.

The considered system is a full passive wind turbine (WT) battery charger (Figure 1) without active control and with minimum number of sensors as studied in [6, 7]. The wind turbine parameters have been obtained by applying similitude relationships with reference to a $1.7 \mathrm{~kW}$ wind turbine which had been previously optimized by an Integrated Optimization
Design (IOD) in [7]. The model of the wind turbine is based on a "mixed reduced model" described in [8]: this model neglects the electrical mode effect but simulates the mechanical one, especially due to the turbine inertia. In order to simplify the modelling approach and to limit the computation cost, the DC bus voltage is supposed to be constant, whatever the battery state of charge: it has been proved in other studies $[8,9]$ that this assumption is acceptable and does not question the battery sizing accuracy. This simplified model has then been chosen due to its computation efficiency which authorizes to analyze system couplings (wind turbine - battery - load) with environment (wind cycle) influence.

Both wind speed and load profiles used in this study are deterministic data. The load profile is set on 24 hours and day by day repeated (Figure 2). The wind speed profile is obtained in a previous study [10] by applying a "compact synthesis process" on an actual wind speed profile of 200 days duration considered as reference data, with the aim of generating a compact profile on a reduced duration of 10 days (Figure 3) to accelerate the optimization process.

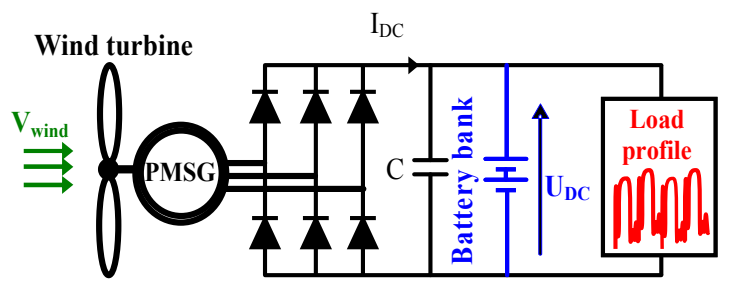

Figure 1. WT system with battery for stand alone application (rural site electrification)

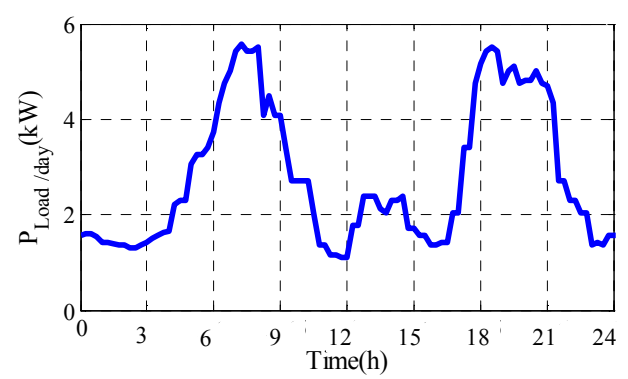

Figure 2. Typical farm load profile for one day 


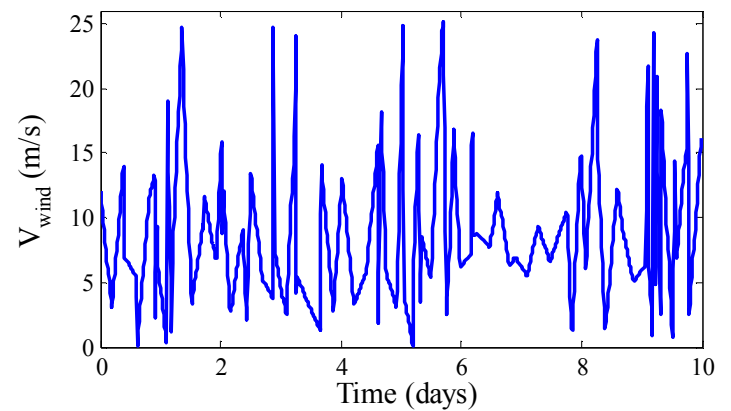

Figure 3. Wind speed profile

TABLE I. BASIC CHARACTERISTICS OF A YUASA NP 38-12I LEAD ACID BATTERY ELEMENT

\begin{tabular}{|c|c|}
\hline Nominal capacity $\mathrm{C}_{3}$ & $30,3(\mathrm{Ah})$ \\
\hline Nominal voltage $\mathrm{V}_{0}$ & $12(\mathrm{~V})$ \\
\hline Nominal discharge Current $\mathrm{I}_{3}$ & $10.1(\mathrm{~A})$ \\
\hline
\end{tabular}

In this study, a lead acid Yuasa NP 38-12I [11] is considered as battery element. The basic characteristics are summarized in the TABLE I.

\section{SYSTEMIC OPTIMIZATION PROBLEM PROCEDURE}

In order to handle the optimization problem of the passive WT submitted to a consumption profile and a given wind speed, we have agreed to adopt an approach based on two optimization levels: Level 1: Local Optimization (LO) and level 2: Systemic Optimization (SO).

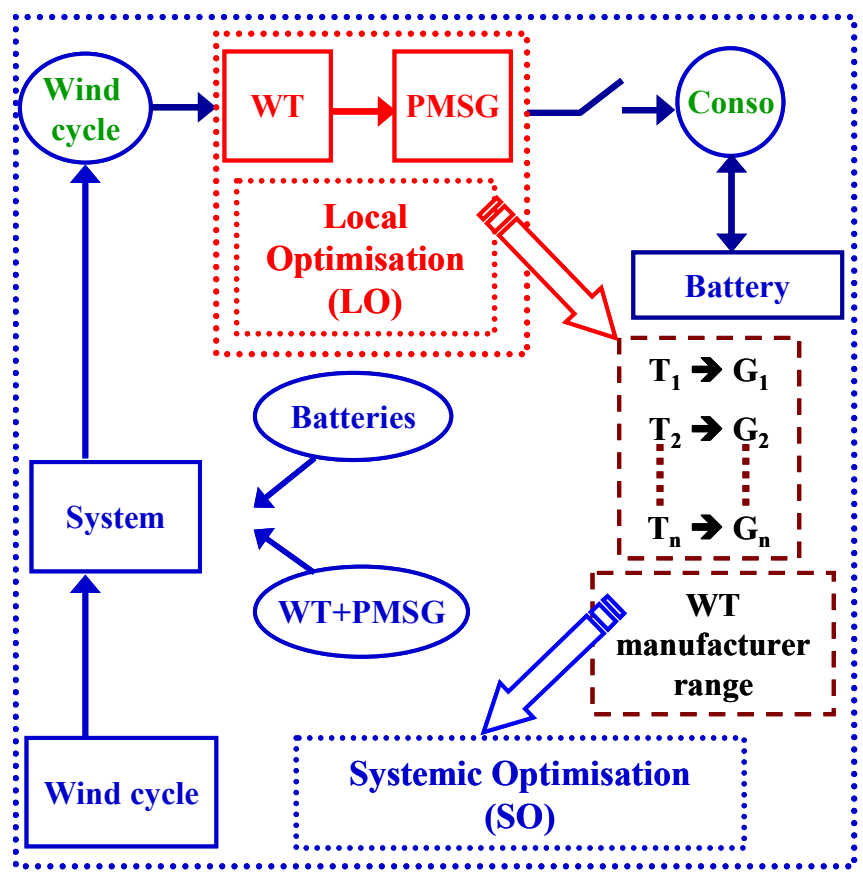

Figure 4. Systemic optimization process

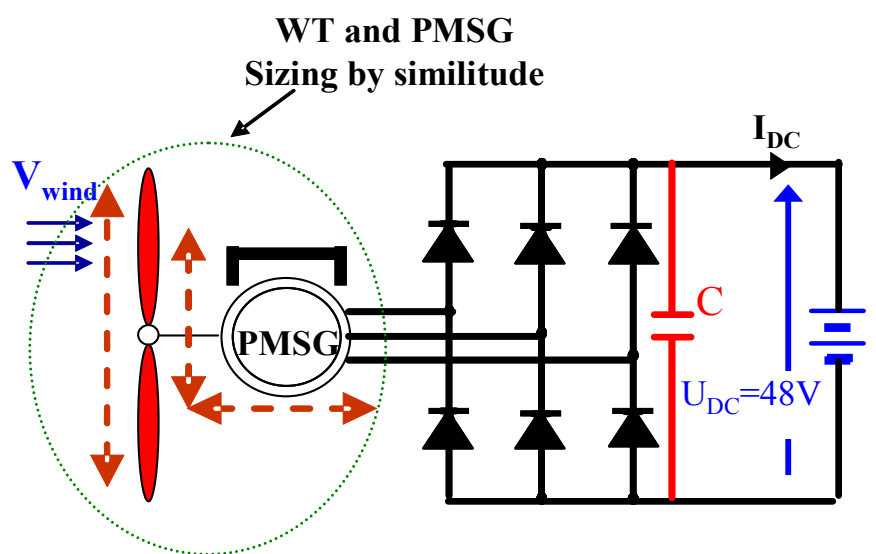

Figure 5. Passive WT synoptic

For a given wind speed profile, the SO approach consists in looking for, in a range of a given WT manufacturer (WT $T_{1}$ to $T_{n}$ and the corresponding PMSG $G_{l}$ to $G_{n}$, which are derived from the LO process), the couple $\left(T_{i}, G_{i}\right)$ and the corresponding storage size which serve a given load demand at lowest owning system cost. This compromise can be obtained by solving the optimization problem illustrated in Figure 4.

\section{LOCAL OPTIMIZATION}

The aim of this first level of optimization is to build a range of $n$ PMSG corresponding to $n$ WT which will be used in the second level of optimization (systemic approach). In this approach, we consider the battery voltage as constant and equal to $48 \mathrm{~V}$ (Figure 5) and we adopt the "mixed reduced model" in the optimization process.

In [9], an IOD method, based on multiobjective optimization, has been developed for sizing the elements of a $1.7 \mathrm{~kW}$ passive wind turbine system (Figure 6). The range of WT and PMSG parameters for various nominal powers had been obtained by applying similitude relationships with reference to the $1.7 \mathrm{~kW}$ wind turbine system [8]. Figure 7 shows the extracted powers of the new passive wind turbines (till $16 \mathrm{~kW}$ ) obtained by similitude from the reference structure (i.e. a $1.7 \mathrm{~kW}$ ) optimized passive wind turbine. It can be seen that the quality of wind power extractions of these passive configurations (red curves) matches very closely the behaviour of active wind turbine systems operating at optimal wind powers by using an MPPT control device (i.e. the green cubic curves on Figure 7).

\section{SYSTEMIC OPTIMIZATION}

The aim of the SO stage is the minimization of the total owning cost on a life cycle of 20 years of the passive WT associated to the storage bank ensuring the electrification of the isolated farm under a specific wind speed cycle. To achieve this optimization process, we have to determine an economic model for each component of the system.

\section{A. WT cost model}

Generally WT subsystem Cost is dispersed between the turbine, nacelle, tower, electrical systems and transmission 
systems. There is no single component that dominates the WT cost. Typical owning costs given by "eaglewestwind" [12] for a range of turbines from $2 \mathrm{~kW}$ up to $20 \mathrm{~kW}$ are shown in Figure 8.

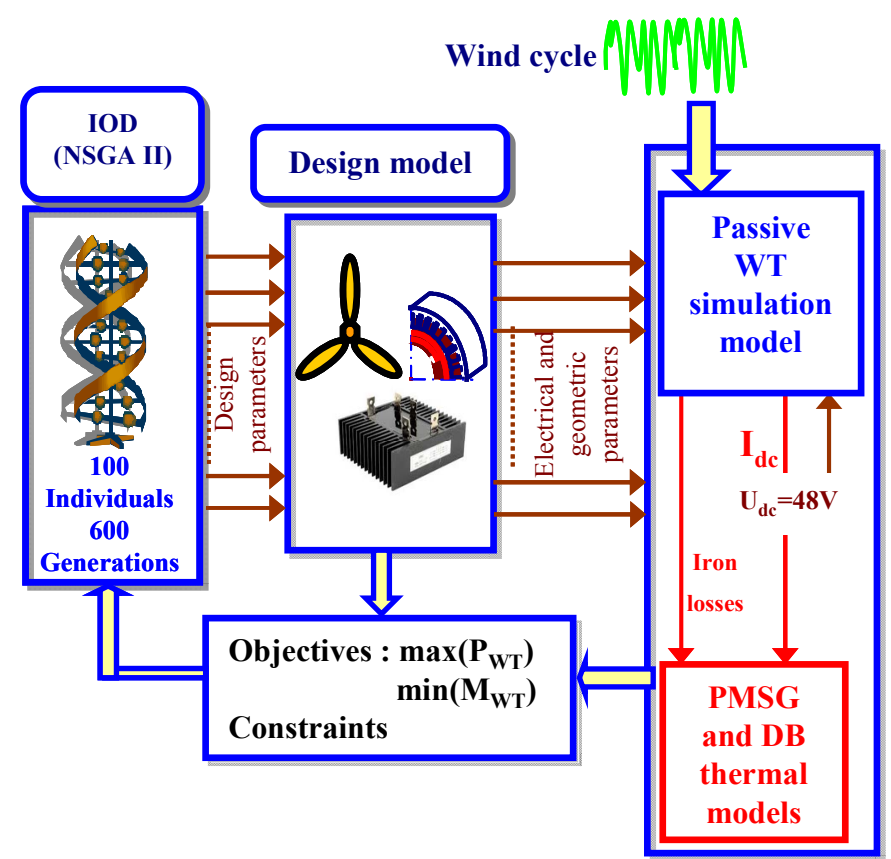

Figure 6. Overview of IOD process for the reference $1.7 \mathrm{~kW} \mathrm{WT}$

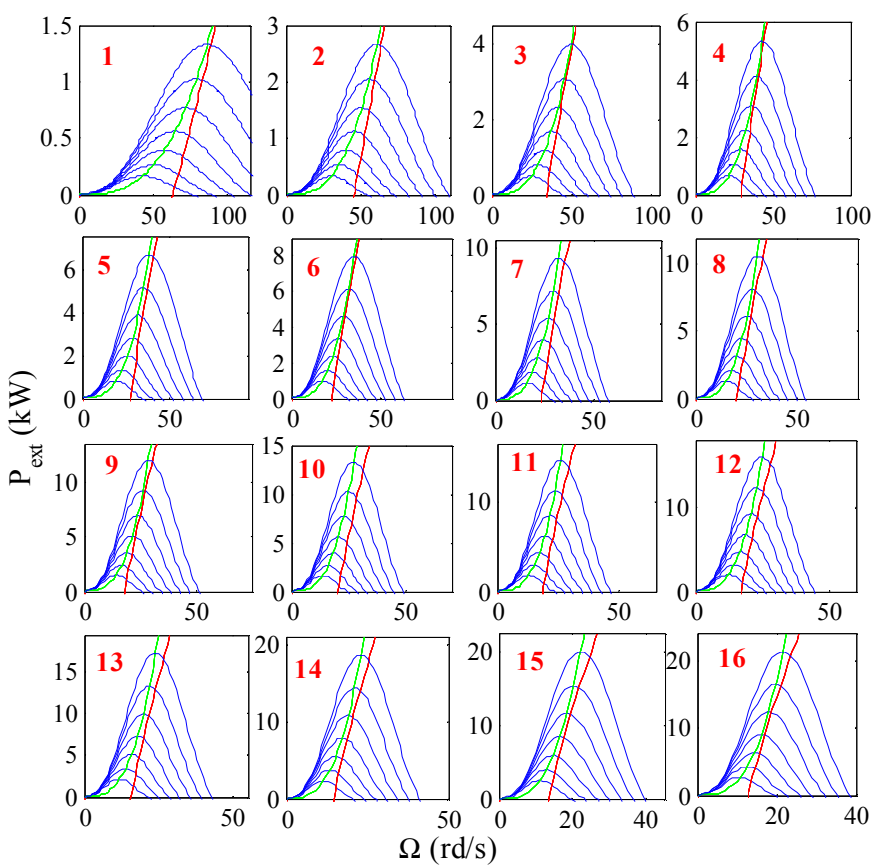

Figure 7. Extracted power of the range of WT systems obtained by similitude from the reference $1.7 \mathrm{~kW} \mathrm{WT}$

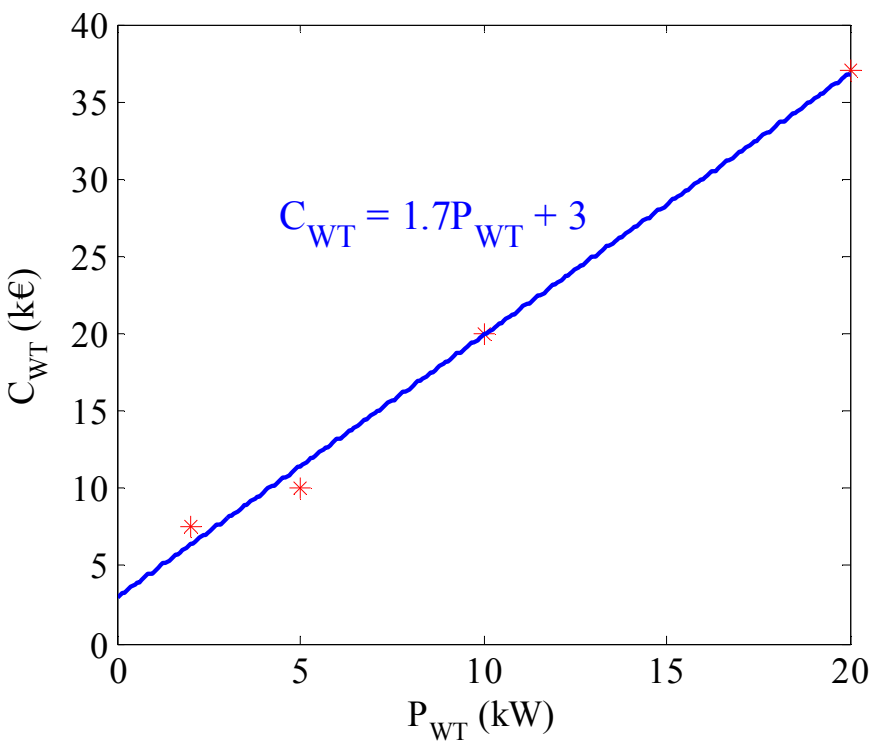

Figure 8. Assumption of a WT cost model for a nominal wind power $\mathrm{P}_{\mathrm{WT}}$

\section{B. Battery bank cost model}

The battery cost depends on the charge and discharge cycles that the battery leads (because battery life is dependent on both depth and rate of discharge). The lifetime model uses a double exponential curve fit (Figure 9) to commonly available cycles to failure (CF) versus. Depth Of Discharge (DOD) [13, 14]:

$$
C_{F}=177.77+7807 \cdot 39 \cdot e^{-6.75 \cdot D O D}
$$

A cycle counting algorithm known as "rainflow cycle counting", based on that proposed for material fatigue by Downing and Socie [15], is used to identify the battery number of cycles $\left(N_{C Y C}\right)$.

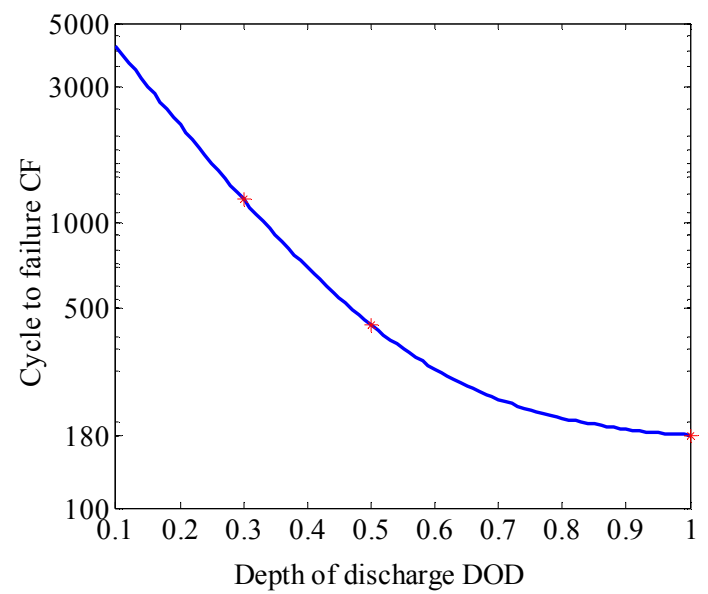

Figure 9. Battery Yuasa cycle to failure curve

For an operating term $\tau_{o p}$ of 20 years and a wind cycle term $\tau$ of 10 days, the approximate cost of the battery bank over 20 years is expressed by the following equation: 


$$
C_{B A T}(k \epsilon)=N_{c e l_{-} s} \cdot N_{c e l_{-} p} \cdot C_{0} \times 10^{-3} \cdot N_{C Y C}^{\tau} \cdot \frac{\tau_{o p}}{\tau}
$$

with $N_{c e l s}$ is the number of battery cells associated in series, $N_{c e l p}$ is the number of battery cells associated in parallel and $C_{0}$ cost cycle battery estimated at $0.1 €[11]$ (Yuasa $12 \mathrm{~V}$ battery cost is $108 €$. Then, the $2 \mathrm{~V}$ battery cell cost is $C_{\text {Cell }}=108 / 6 €$ and 180 deep cycles cost $C_{\text {Cell }}$. Finally, 1 cell deep cycle costs $\left.C_{\text {Cell }} / 180=0.1 €\right)$.

\section{C. optimization problem formulation}

The problem is to develop a systemic approach that designs optimal system configurations (passive WT with storage bank) that satisfy customer desired reliability criteria .with minimum total system cost. The total system cost calculation includes the WT owning cost and battery bank owning cost. The systemic optimization process is detailed in Figure 10.

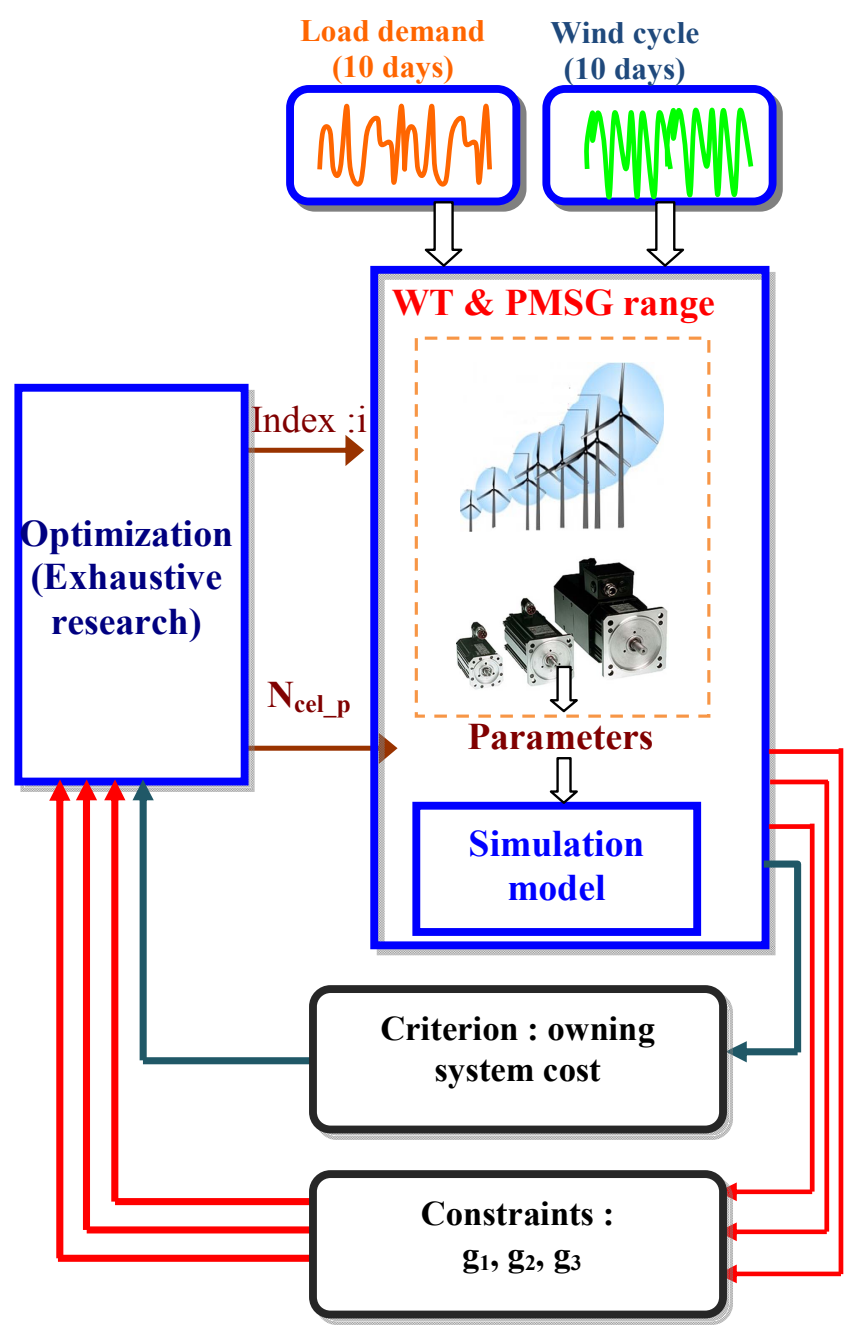

Figure 10. Systemic process of optimal design

\section{Objective function}

Our choice has been made to pursue the analysis using an objective function optimisation representing the total owning cost which includes the WT and the battery bank owning costs over a duration period of 20 years.

$$
O b j=C_{S Y S}=C_{W T}+C_{B A T}
$$

\section{E. Design variables}

The optimization problem uses only two design variables:

- Ncel $p$ : The number of battery cells associated in parallel.

- index $i$ : The index identifies the $T_{i}$ and $G_{i}$ among the pre-constructed set of WT whose the parameters will be used by the simulation bloc to calculate the objective function and constraints.

Ncel $\_$and index $i$ are considered as discrete variables

\section{F. Optimization constraints}

- $g_{1}$ :Constraint related to the maximum discharge current ( Iis_max $\left._{\text {max }}\right)$

The battery cell maximum discharge current $\left(\max \left(I_{c e l}\right)\right)$, must be less than the current $I_{\text {dis_max }}$ :

$$
g_{1}=\max \left(I_{c e l}\right)-I_{\text {disch_max }} \leq 0
$$

- $g_{2}$ :Constraint related to maximum charge current $\left(I_{c h \_ \text {max }}\right)$

The absolute value of the maximum battery cell charge current ( $\left.\left|\min \left(I_{c e l}\right)\right|\right)$ must be less than the current $I_{\text {ch-max }}$ :

$$
g_{2}=\min \left(I_{c e l}\right)-I_{c h} \max \leq 0
$$

- g3: Constraint related to the battery cell State Of Charge (SOC)

The minimum value of the battery cell state of charge of a $(\min (S O C(t)))$, must be greater than 0.2 :

$$
g_{3}=20 \%-\min (\operatorname{SOC}(t)) \leq 0
$$

In this study, $I_{d i s_{-} \max }$ and $I_{c h \_ \text {max }}$ have been chosen equal to 10.1 A (TABLE I).

As defined, the optimization problem order of complexity is very low (two design variables and three constraints), which justifies the use of an exhaustive search instead of adopting a sophisticated algorithms of optimization (such as evolutionary algorithms).

\section{RESULTS AND ANALYSIS}

As mentioned, the goal of our study has been to optimise the design of a passive WT with a storage bank under specific environmental conditions (wind speed and load profiles) in order to minimize the owning system cost. Figure 11 shows a set of solutions resulting from the systemic optimization process, corresponding to an owning system cost less than 
$118 \mathrm{k} €$ and Figure 12 shows the equivalent battery bank cost. Each point corresponds to one solution, (i.e. one genome of variables: index $i$ representing the WT nominal power and $N_{c e l}$ p).

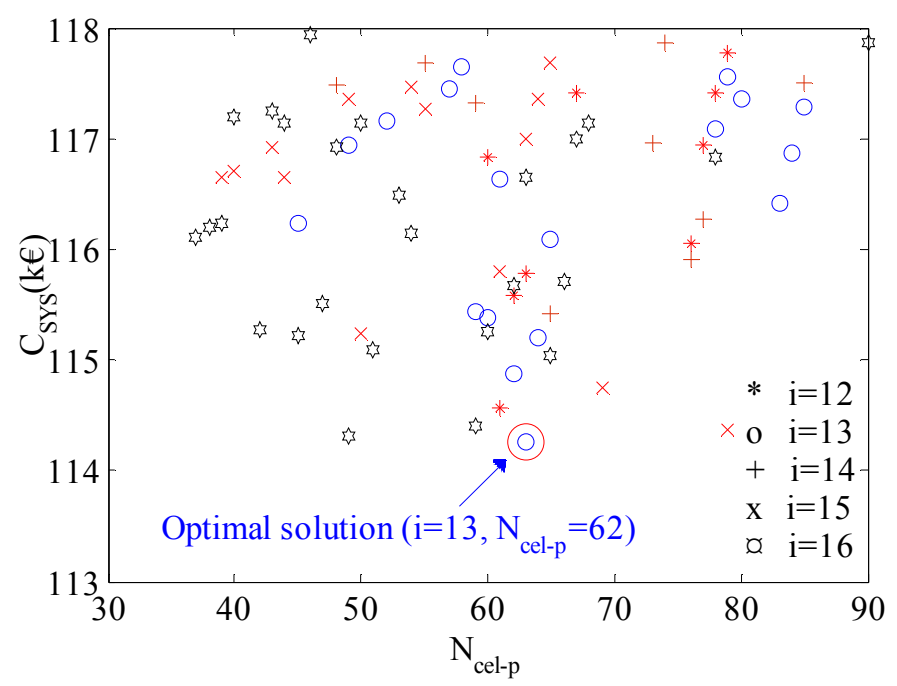

Figure 11. Owning system cost

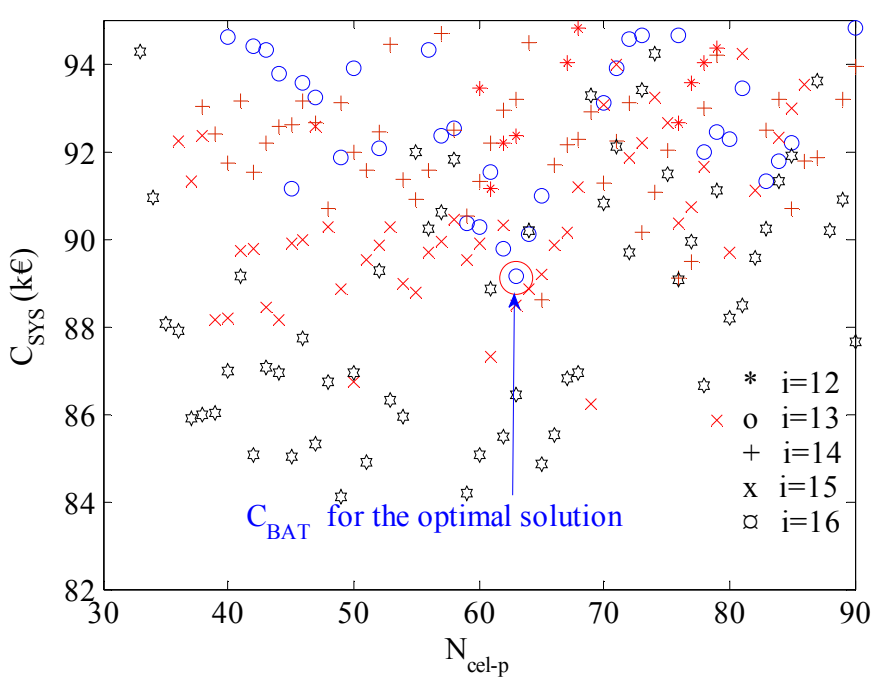

Figure 12. Battery bank cost

The cheapest solution (circled in red in Figure 11 and Figure 12) is to connect 63 battery cells with a WT of $13 \mathrm{~kW}$ of nominal power $(i=13)$. TABLE II shows the different characteristics of this solution and Figure 13 shows the state of charge $S O C$ and the battery cell current $\left(I_{c e l}\right)$ evolutions.

TABLE II. OPTIMAL SOLUTION CHARACTERISTICS

\begin{tabular}{|c|c|}
\hline Design variables and costs & Optimal values \\
\hline$N_{\text {cel_p }}$ & 63 \\
\hline
\end{tabular}

\begin{tabular}{|c|c|}
\hline Index $i$ & 13 \\
\hline$C_{W T}(\mathrm{k} €)$ & 25.1 \\
\hline$C_{B A T}(\mathrm{k} €)$ & 89.1 \\
\hline$C_{S Y S}(\mathrm{k} €)$ & 114.26 \\
\hline
\end{tabular}
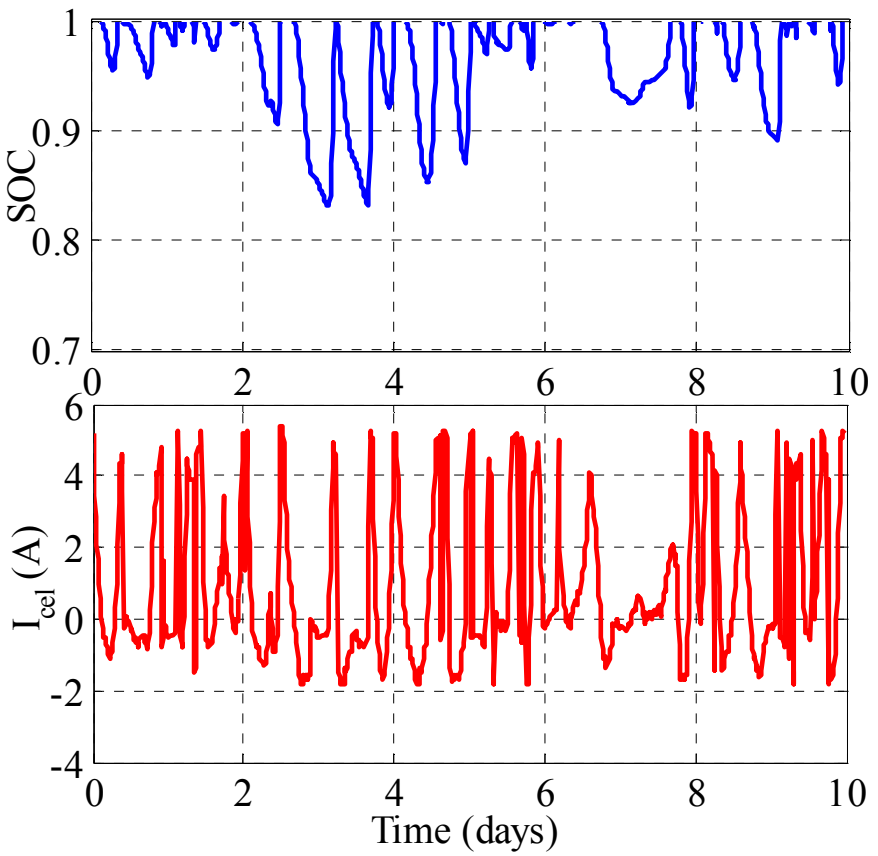

Figure 13. SOC and $I_{c e l}$ evolutions for the optimal solution

The analysis of the results given by Figure 11 and Figure 12 illustrates that some solutions with different characteristics have almost the same owning system cost. Especially, solutions indexed 15 and 16 whose the $C_{B A T}$ are the cheapest among others configurations. Thus, the choice of the solution indexed 13 is not surely the most pertinent solution. Therefore, it is interesting to analyze these solutions by a sensitivity analysis versus changes of environmental data (wind speed and load) or rebuilt the whole problem through a robust design optimization in order to extract the optimal solution. This work will be the purpose of our future researches.

\section{CONCLUSION}

This paper illustrates a systemic optimization approach devoted to the optimal design of a full passive WT with storage. The optimization problem was divided into two processes: local Optimization who's the goal to construct a set of optimized WT in order of their use in the second optimization level: systemic optimization. The systemic optimization objective is to minimize the total owning system cost. Results were shown and discussed and a proposal was set to eventual sensitivity analysis study versus changes of environmental data.

\section{ACKNOWLEDGMENT}


This work was supported by the Tunisian Ministry of High Education, Research and Technology; CMCU- 12G1103 and INPT SMI projects.

\section{REFERENCES}

[1] B.S. Borowy, Z.M. Salameh, "Methodology for optimally sizing the combination of a battery bank and PV array in a Wind/PV hybrid system", IEEE Transactions on Energy Conversion, Vol. 11, No. 2, pp. $367-375,1996$.

[2] D.J. Spiers and A.D. Rasinkoski. «Limits to battery lifetime in photovoltaic applications ». Journal of Power Sources, pp. 123, 1997.

[3] J. L. Bernard-Agustín, R. Dufo-Lopez, D. M. Rivas-Ascaso, "Design of isolated hybrid systems minimizing costs and pollutant emissions", Renewable Energy, Vol. 31, No. 14, pp. 2227-2244, November, 2006.

[4] T. Senjyu, D. Hayashi, A. Yona, N. Urasaki, T. Funabashi, "Optimal configuration of power generating systems in isolated island with renewable energy", Renewable Energy, Vol. 32, pp. 1917-1933, 2007.

[5] R. Belfkira, C. Nichita, P. Reghem, G. Barakat, "Modeling and optimal sizing of hybrid energy system", International Power Electronics and Motion Control Conference (EPE-PEMC), September 1-3, Poznan, Poland, 2008

[6] M. Belouda, J. Belhadj, B. Sareni, X. Roboam, "Battery sizing for a stand alone passive wind system using statistical techniques", $8^{\text {th }}$ International Multi-Conference on Systems, Signals \& Devices, Sousse, Tunisia, 2011
[7] A. Mirecki, X. Roboam, F. Richardeau, "Architecture cost and energy efficiency of small wind turbines: which system tradeoff?", IEEE Transactions on Industrial Electronics, Vol. 54, No. 1, pp. 660-70, 2007.

[8] Y. Fefermann, S. A. Randi, S. Astier, X. Roboam, "Synthesis models of PM Brushless Motors for the design of complex and heterogeneous system', EPE'01, Graz, Austria, September 2001.

[9] B. Sareni, A. Abdelli, X. Roboam, D.H. Tran, "Model simplification and Optimization of a Passive Wind Turbine Generator", Renewable Energy Journal, Vol.34, pp. 2640-2650, 2009.

[10] M.Belouda, J.Belhadj, B. Sareni, X. Roboam, J. Amine: "Synthesis of a compact wind profile using evolutionary algorithms for wind turbine system with storage", MELECON'2012, Hammamet, Tunisia, Mars 2012.

[11] http://www.houseofbatteries.com/pdf/NP38-12

[12] http://www.eaglewestwind.com/

[13] S. Drouilhet and B.L Johnson. "A battery life prediction method for hybrid power applications" $35^{\text {th }}$ AIAA Aerospace Sciences Meeting and Exhibit, Reno, Etats-Unis, janvier 1997.

[14] A.J. Ruddella, A.G. Duttona, H. Wenzlb, C. Ropeterb, D.U. Sauerc, J. Mertend, C. Orfanogiannise, J.W. Twidellf, and P. Vezing. "Analysis of battery current microcycles in autonomous renewable energy systems". Journal of Power Sources, pp. 123 - 124 and 136, 2002.

[15] S. D. Downing, and D. F. Socie, "Simple Rainflow Counting Algorithms", International Journal of Fatigue, January, pp. 31, 1982. 